not refer to the relative frequencies of classes in the $F_{2}$ progeny from a cross between pure lines. Galton's ratio refers to the relative frequencies of white, grey and black structural units (or cells) which constitute the $\mathrm{F}_{\mathbf{1}}$ grey hybrid individual. Indeed Galton himself wrote that "the hybrid between white and black forms was exactly intermediate, viz. gray-thenceforward forever".* Moreover, the last part of the letter: "If there were two gemmules only ... Pascal's triangle" is actually the development of the preceding sentence: "The larger the number of gemmules in each organic molecule, the more uniform will the tint of grayish be in the different units of structure". The strict correspondence between the elements of these two propositions leaves no doubt about the sense of "cases", which refer to the units of structure in a $\mathbf{F}_{\mathbf{1}}$ hybrid individual.

Secondly, was Galton really reasoning about the basic assumption that " inheritance is due to a finite number of persistent particles". In other words, did he ever assume the first Mendelian law of alternative inheritance? This is doubtful. Indeed Galton's argument is based on the pangenetic assumption that each cell of the organism gives off " minute granules, or atoms, or gemmules". Were these gemmules thought to persist with their original characteristics from one generation to the next? More precisely: what kind of hereditary material, or gemmules, will the $F_{1}$ hybrids produce? (see fig. $1, \mathrm{~F}_{1}$ : a, b, c, n). As far as we know nowhere does Galton go into this important question.

"The inception of an important branch of science is seldom traceable to a single work of a single investigator. This is possible with genetics. Genetics takes its rise from the work of Gregor Johann Mendel " (Dobzhansky, 1964). We believe that Sir Francis Galton's letter, in spite of its interest, does not invalidate this assertion.

\title{
REFERENCES
}

DOBZHANSKy, TH. 1964. The Mendel centennial. The Rockefeller Institute Review, 2, 1-6. OLBY, R. C. 1965. Francis Galton's derivation of Mendelian ratios in 1875. Heredity, 20, 636-638.

OL.BY, R. C. 1966. Origins of Mendelism. Constable, London. 204 pp.

\section{GALTON'S RATIOS}

\author{
R. C. OLBY \\ Botany School, Oxford
}

Received 25.ix.67

IN interpreting statements from the past it is, admittedly, all too easy to read into them with the aid of hindsight what is not really there. At the same time it is only just to give recognition to those who adumbrate a fundamental concept.

* One could suppose that the words " thenceforward forever" were used by Galton to express the idea that the greyish character would persist in the sexual offspring of the $F_{1}$ hybrids. This is not the case. These words refer to the vegetative multiplication of the hybrid and form part of Galton's answer to a precise statement of Darwin's, that "If two plants are crossed, it often or rather generally happens that every part of (the) stem, leafeven the hairs-and flowers of the hybrid are intermediate in character; and this hybrid will produce by buds [our italics] millions on millions of other buds all exactly reproducing the intermediate character". 
When we attempt to assess the meaning of Galton's letter to Darwin, let us bear in mind the following points :

(1) Before writing the letter under discussion Galton had conceived the idea of the continuity of the germplasm, though he was less decisive than Weismann about its inviolability. He believed that gemmule-like hereditary elements did exist, but doubted that transmission of gemmules took place from somatic to reproductive tissues.

(2) Nowhere in his publications did he allow the fusing of gemmules; division, yes; loss, yes, but no loss of identity. He attributed the various degrees of blending in the phenotypic ("patent" in Galton's language) expression of contrasting qualities to variation in the number and type of organic units.

(3) The correspondence under discussion concerns the question: If a hybrid shows a blend of parental qualities, are not its gemmules also blended or fused together? Galton's reply sets out how the macroscopic appearance of blending can be caused by an underlying set of non-blending units. This view of the matter is also stated in his other publications (Galton, 1869, $1875,1889)$.

I regret having identified Galton's "cases" too readily with hybrid progeny, and I accept the opinion of Lints and Delcour in this issue that Galton was referring to the cells of the $F_{1}$ hybrid. On the other hand I still see every reason for recognising Galton's letter of 1875 together with his publications during the period 1872-75 as the closest approach to Mendelian theory that any nineteenth-century biologist made. Despite the opinion of Lints and Delcour I still maintain that Galton's theory of inheritance is particulate, that he believed inheritance to be due to a constant and finite number of particles, and that this number can be determined by a statistical analysis of populations.

\section{References}

Galton, F. 1869. Hereditary Genius. John Murray, London.

Galton, F. 1875. 7. anthrop. Inst., 5, 329-348.

Galton, F. 1889. Ancestral Inheritance. John Murray, London. 